\section{Novel ERCP technique using a pushing catheter as a "mini-overtube" to remove a migrated metal stent from the bile duct}

The use of fully-covered self-expanding metal stents (FCSEMSs) for benign and malignant biliary diseases is well established [1]. Whereas migration out of the bile duct is not uncommon, inward migration is rare and much more difficult to manage [2]. We report on a new technique to remove an internally migrated FCSEMS.

A 51-year-old woman with Caroli's disease, sclerosing cholangitis, and severe hepatolithiasis had been undergoing repeated endoscopic retrograde cholangiopancreatographies (ERCPs) with stone extraction and stenting to palliate her condition while awaiting liver transplantation ( Fig.1a). Because of the presence of huge bile duct stones, an FCSEMS (Boston Scientific, Natick, Massachusetts, USA) was inserted into the bile duct, with resulting regression of her cholestasis. On follow-up ERCP, however, the stent had migrated completely into the bile duct. Removal of the stent was impossible using standard devices such as baskets, balloons, snares, and standard forceps. Furthermore, insertion of a rat-tooth forceps into the bile duct was impossible because of the small ampullary orifice and the stiffness of the shaft of the forceps.

A solution to the problem was therefore sought. A pushing catheter (Cook Medical, Winston-Salem, North Carolina, USA) was inserted into the bile duct, and this served as a "mini-overtube" for the rat-tooth forceps to advance freely deep into the bile duct. The following steps describe the technique.

First, a guidewire (Metro; Cook Medical) was advanced through the stent using the U-wire or flipped-wire technique [3] ( Fig. 1 b). Second, a pushing tube from a $10-$ Fr plastic stent device was advanced over the wire and into the bile duct
( $\nabla$ Fig.1 c). Third, the wire was removed and the rat-tooth forceps was fed through the pushing tube ( $\bullet$ Fig. $1 d$ ). The presence of the pushing catheter, acting as a mini-overtube, allowed for adequate positioning of the rat-tooth forceps at the distal edge of the stent, which was successfully grasped ( $\bullet$ Fig. 1 e,f) and removed (๑ Fig. 1 g, h).

\section{Endoscopy_UCTN_Code_TTT_1AR_2AZ}

\section{Competing interests: None}

\section{Carolina Olano, Klaus Mönkemüller}

Basil I. Hirschowitz Endoscopic Center of Excellence, Division of Gastroenterology and Hepatology, University of Alabama at Birmingham, Alabama, USA

\section{Acknowledgment \\ $\nabla$}

Dr. Carolina Olano performed this work during her visiting professorship at the Basil I. Hirschowitz Center of Endoscopic Excellence, Division of Gastroenterology, University of Alabama at Birmingham, USA.
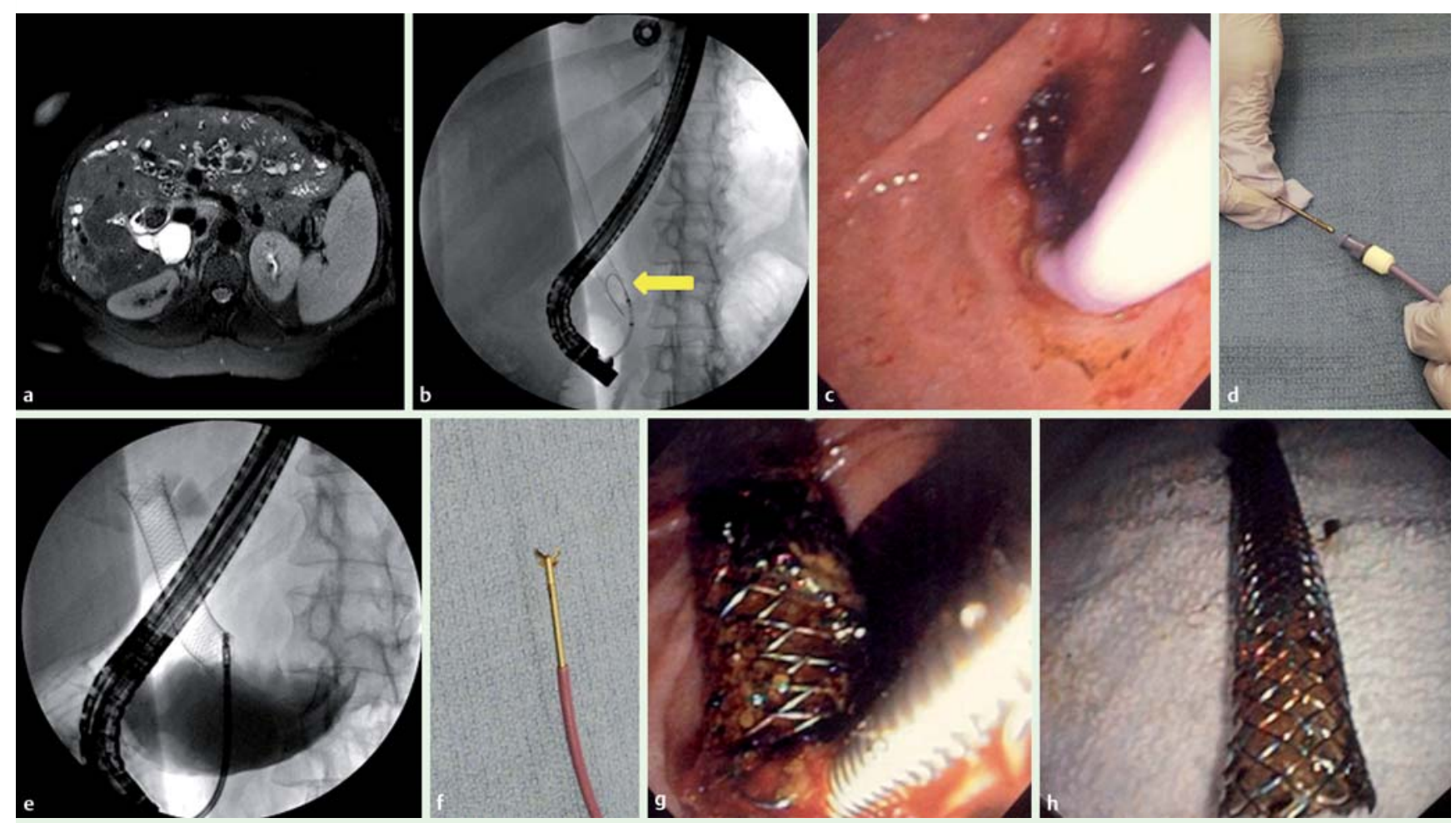

Fig. 1 a Magnetic resonance imaging (MRI) showing Caroli's disease, sclerosing cholangitis, and severe hepatolithiasis. b A guidewire was advanced through the stent using the U-wire or flipped-wire technique. $\mathbf{c}$ A pushing tube from a 10-Fr plastic stent device was advanced over the wire and into the bile duct. $\mathbf{d}$ The wire was removed and the rat-tooth forceps was fed through the pushing tube. e The presence of the pushing catheter ("mini-overtube") allowed for adequate positioning of the rat-tooth forceps at the distal edge of the stent, which was successfully gasped. $\mathbf{f}$ The rat-tooth forceps is seen exiting the pushing catheter, which served as a "mini-overtube". $\mathbf{g}$ The rat-tooth forceps tightly grasped the end of the stent, which was then removed. $\mathbf{h}$ The stent was removed without being fractured. 


\section{References}

1 Kahaleh M, Behm B, Clarke BW et al. Temporary placement of covered self-expandable metal stents in benign biliary strictures: new paradigm? Gastrointest Endosc 2008; 67: 446-454

2 Cho NJ, Lee TH, Park SH et al. Endoscopic removal of a proximally migrated metal stent during balloon sweeping after stent trimming. Clin Endosc 2013; 46: 418-422

3 Liu F, Zhu JY, Li ZS. The "U-wire" technique during ERCP for easy guide wire passage through occluded uncovered metal stents. Endoscopy 2012; 44: E116
Bibliography

Dol http://dx.doi.org/

10.1055/s-0034-1377637

Endoscopy 2014; 46: E534-E535

(c) Georg Thieme Verlag KG

Stuttgart · New York

ISSN 0013-726X

\section{Corresponding author}

\section{Klaus Mönkemüller, MD, PhD}

Division of Gastroenterology and Hepatology Basil I. Hirschowitz Endoscopic Center of Excellence

Endoscopy Unit, JT 664

619 19th Street $S$

Birmingham, AL 35249

USA

Fax: +1-205-934-1537

klaus1@uab.edu 